\title{
Heat Transfer Analysis and Performance Measurements of Hollow Pin-fin in Natural Convection
}

\author{
Chandrakishor L. Ladekar, Sanjeo. K. Choudhary
}

\begin{abstract}
The Fin act as dissipiating elements, selection of proper geometry plays crusial role in increasing the rate of heat transfer and performance of the system. This work has been undertaken to investigate and compare thermal performance of solid and hollow pin-fin. Heat transfer analysis of solid and hollow pin fin carried and the results was compared with the experimental results. experiment was conducted to analyze the natural convection around solid hollow pin fin, and compare thermal performance of hollow pin fin with the solid pin fin of same dimension and orientation. The experimental result of temperature distribution shows that the faster temperature drop along the length. The high value of convective heat transfer in the initial phase due to which faster temperature drop takes place. Convection is found to be dominating due to less area for conduction along the length. Theoretical value and experimental value are close to each for temperature distribution as well the convective heat transfer coefficient. Efficiency is reduced in the case of hollow fin but the effectiveness of the hollow pin fin is increased by 1.76 times from an economical point of view, holoow pin fin is more efficient solution.
\end{abstract}

Keywords: Pin-fin, Hollow Pin-fin, solid pin fins, Natural convection, Thermal Performance, Heat Transfer Analysis

\section{INTRODUCTION}

Nowadays, pin fins are extensively used to enhance heat transfer to ambient air. The development of high power electronic components, the miniaturization of electronic devices and the demand for greater functionality, larger storage space and faster rates of information transfer for portable electronic devices have increased drastically. As more electronics are packed into smaller spaces, the heat removal requirements for these devices become increasingly demanding, and as a result, traditional heat sink cooling mechanism may not be applicable anymore hence the use of pin fins is increased.

Pin fin provides the most powerful heat sink designs available today. Pin fin heat sinks provide very low thermal resistance values per given space and low-pressure drop. The cooling

Revised Manuscript Received on July 22, 2019.

Dr. Chandrakishor L. Ladekar, Assistant Professor in the Mechanical Department, Pimpri Chinchwad College of Engineering, Pune-411 044, India,

Dr. Sanjeo. K. Choudhary, Professor in Mechanical Engineering Department, KDK College of Engineering, Nagpur-411 044, India, capabilities of pin fins stem from the round geometry of the pins, the unidirectional pin configuration, and the use of highly conductive materials.

The design of the heat sink device is based on the criterions of maximizing thermal dissipation rate. Pin fin array is one of the most common solutions applied to heat sink designs. For instance, Sparrow et al. [1] examined the performances of in-line and staggered-pin fin arrays based on the thermal dissipation and pressure drop criterions. The results revealed that heat dissipation and pressure drop for staggered arrays are always better than those for the in-line arrangements. Bilen et al. [2] examined the heat transfer and friction correlation of cylindrical finned surface experimentally. The thermal performances for in-line and staggered- pin fin arrays were compared with the heat sink without pins. Results indicated that the thermal enhancement for pin fin arrays is better than the heat sink without pins and the thermal dissipation for staggered pins is about 33\% higher than that for in-line arrangement at the same Reynolds number.

Besides, several researchers have examined the influences of the pin geometry and configurations on the thermal performances. There are varieties of heat sink types, with differing fin geometries and operating with natural or forced convection [3]. A common geometry is a pin fin array heat sink. However, the rationale for selecting a particular design of heat sink or more specifically a particular fin cross-sectional profile remains somewhat uncertain.

Chapman et al. [4] experimentally investigated the air side thermal performance of pin fin heat sinks with square, circular and elliptical cross-section and found that elliptical pin fins are superior on airside performance in forced convection. Khan et al. [5] analytically developed a forced convection model for determining heat transfer from in-line and staggered pin-fin heat sinks used in electronic packaging applications and examined the effect on overall thermal/fluid performance associated with different fin geometries including rectangular plate fins as

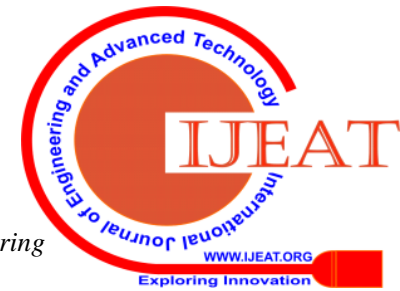


well as square, circular and elliptical pin fins. An experimental study was performed by Yang et al. [6] for pin fin heat sinks having circular, elliptic and square cross-section with inline and staggered arrangements to study the effect of fin density on the heat transfer performance. The work on numerical investigations for elliptical pin fin heat sinks was reported by Seyf et al. [7].

Influences of the pin geometry and configurations on the thermal performances were examined by several researchers, For example, Meinders et al. [8] indicated that the size of the recirculation flow behind the pins affects significantly the local heat dissipation rate. Sara et al. [9] studied the heat-transfer enhancement and the corresponding pressure drop over a flat surface in a channel flow due to perforated rectangular cross-sectional blocks attached on its surface. They found that for the perforated blocks, the higher the perforation diameter, perforated area open-area ratio, and the inclination of perforation holes, the better the overall energy performance.

Shaeri and Yaghoubi [10] investigated numerically a three-dimensional fluid flow and convective heat transfer in an array of solid and perforated fins that are mounted on a flat plate. Results indicated that the rate of heat transfer in perforated fins is much higher than that in the solid fins due to its larger surface area to volume ratio. Besides, the total drag coefficient of the solid fins is much higher than that of the perforated fins. Finally, numerical computations are validated with previous experimental studies and good agreements were obtained.

Ismail et al. [11] examined various types of perforations in the form of small channels such as square, circular, triangular and hexagonal cross sections and the thermal performances of those types of perforations are compared to improve the cooling performance of heat sink. Results show that circular perforation fins have the best thermal and fluid dynamic performances than the other types of fins considered in their work.

Chin et al. [12] examined experimentally and numerically the heat sink modules with staggered perforated pin fins and the objective is to design the heat sink modules with best heat dissipation rate by considering the effects of the number of perforations and the diameter of perforation on each pin. Results indicated that heat dissipation decreases significantly when the ratio of pin diameter to perforation diameter exceeds 0.375 and the Nusselt number of the perforated pins is $45 \%$ higher than that of the solid pins and it increases with the number of perforation. Finally, they concluded that pin fins have five perforations and the perforated diameter equal to $3 \mathrm{~mm}$ offer the best performance. In their study the perforation diameters of perforated pin fins are assumed, all the same, they did not consider the perforation diameters as the design variables and apply the optimization technique to perform the design process.

Further, mixed or combined free and forced convective heat transfer arise in many transport processes in engineering devices and in nature [13] which is frequently encountered in industrial and technical processes including electronic devices cooled by fan, nuclear reactors cooled during emergency shutdown, heat exchangers placed in a low-velocity environment, solar receivers exposed to winds, etc. At low velocities, the presence of temperature gradient in a fluid in a gravity field always gives rise to natural convection currents. Therefore, forced convection is always accompanied by natural convection both being a strong function of fluid velocity. The error involved in ignoring natural convection is negligible at high velocity but may be considered at low velocities. In the open literature, very few studies are observed dealing with this kind of mixed convection where forced convection is accompanied by natural convection in pin fin heat sink applications.

Deshmukh et al. [14] have documented a comprehensive literature review on the thermal performance of pin fin heat sinks covering all modes of heat transfer, including mixed convection. Kobus et al. $[15,16]$ carried out a comprehensive theoretical and experimental study on the thermal performance of a circular pin-fin heat sink under combined natural and forced convection with the impinging flow.

The present study focuses upon the thermal performance of hollow pin fin subjected to natural convection with assisting flow. The purpose of current work is to indirectly measure the average convective heat transfer coefficient for the hollow pin fin and compare the performance with the solid pin fin. Also, it is aimed at predicting the thermal performance characteristics of the hollow pin fin in terms of various design parameters and to reveal their influence. The experimental investigation for the hollow pin fin will provide design insight including the rate of convection, its temperature distribution, efficiency \& effectiveness of pin fin.

\section{FORMULATION OF A THEORETICAL MODEL}

A theoretical model for predicting the thermal performance of a pin-fin is formulated by considering the heat sink to be made up of a single pin-fin.

\subsection{Assumptions}

This study assumes the following design considerations:

1. Each pin is of uniform cross section and Length, L, with a hollow cross-section. 
2. The pin fin tips are adiabatic.

3. There is no airflow bypass, i.e. the heat sink is fully ducted.

4. The airflow is normal to the pin-axis.

5. Flow is steady and laminar.

6. Radiation heat transfer is negligible.

\subsection{Theoretical model}

The identical shape of the solid pin-fin, hollow pin-fin is selected in terms of length and external diameter. Assuming the material and volume are the same for both the fins, the equivalent diameter of hollow pin fin can be expressed as D, where $\mathrm{D}$ is the diameter of a circular pin-

Using the temperature distribution, along with the Fourier model for conduction, the rate of heat transfer from a single solid \&

hollow pin-fin, Qfin, can be modeled as,

$$
\begin{aligned}
& Q_{f i n}=k m A *\left(T_{b}-T_{f}\right) * \tanh (m L) \\
& \text { Where } m=\sqrt{\frac{h p}{k A}}
\end{aligned}
$$

$\mathrm{h}$ is the convective heat transfer coefficient and can be calculated for natural convection if the temperature conditions are known. Using theoretical analysis convective heat transfer coefficient can be calculated as follow.

Mean film temperature and the temperature difference between surface temperature and atmospheric temperature for Boundary layer are given by equation $2 \& 3$ respectively:

$$
\begin{aligned}
& T_{m f}=\frac{\left(T_{S}+T_{a t m}\right)}{2} \\
& \Delta T=T_{S}-T_{a t m}
\end{aligned}
$$

Since the hollow pin fin can be considered as the hollow cylinder placed horizontally, Rayleigh number ( $R a)$ is calculated using

Grashof number and Prandtl numbers which are given in from equation 4 to equation 6 as follows [17]:

$$
G r=\frac{g \beta \Delta T L c^{3}}{\vartheta^{2}}
$$

Where $\beta=1 / T_{\text {mif }}$ and is the coefficient of volumetric expansion, Also the $\mathrm{Lc}=\mathrm{A} / \mathrm{P}$ is the characteristic length and is considered as D

for the horizontal tube.

$$
\begin{aligned}
& p r=\frac{\mu C_{p}}{k} \\
& R a_{D}=G r_{D}{ }^{*} \operatorname{Pr}
\end{aligned}
$$

As per Churchill and Chu correlation for a horizontal circular cylinder, Nusselt number is given by equation 8 :

$$
\overline{N u_{D}}=\left[0.60+\frac{0.387 R a_{D}^{1 / 6}}{\left\{1+(0.559 / \mathrm{Pr})^{9 / 16}\right\}^{8 / 27}}\right]^{2}
$$

Also morgan correlation for a horizontal circular cylinder, Nusselt number is given by equation 8 :

$$
N u_{D}=C\left(R a_{D}\right)^{\mathrm{n}}
$$

Where the values of $\mathrm{C}$ and $\mathrm{n}$ are based on the range of $\mathrm{RaD}$ and are selected according. Convective heat transfer coefficient is calculated using the equation given below:

$$
N u_{D}=\frac{h D}{k}
$$

A further value of $\mathrm{m}$ is calculated as $\mathrm{m}=\sqrt{\frac{h P}{k A_{c s}}}$ where $\mathrm{A}_{\mathrm{cs}}$ is cross-sectional area and is calculated as $\mathrm{A}_{\mathrm{cs}}=$ $A_{e s}=\frac{\Pi}{4}(D-d)^{2}$.

Calculated $\mathrm{mL}$ vale is found to be less than 2.67 and the cross-sectional area is very very small as compared to surface area therefore for the case of finite length fin with insulated tip the efficiency and effectiveness is calculated using the equation 9 and equation 10 respectively as given below

\section{DESIGN OF EXPERIMENT}

For doing the experimental investigation to evaluate the comparative thermal performance of the hollow pin fin over solid pin fin in natural convection a simple experimental setup was built. Fig. 1 shows the schematic of the experimental setup. The experimental setup consists of the pin fin holding screw and at one of the end, the band heater is supplied for supplying the heat to the pin fin. K-type thermocouples of $\mathrm{Cu}$ constant were used to measure temperature. Five thermocouples were placed equidistance from each other entire length of the test rod. Control panel with good quality and calibrated measuring instruments like the voltmeter, ammeter, dimmerstat, and temperature indicator was used. Temperature with the least count of $0.10 \mathrm{C}$ was used for measuring the temperature and experiment was conducted at steady state several times using the solid fin and hollow fin.

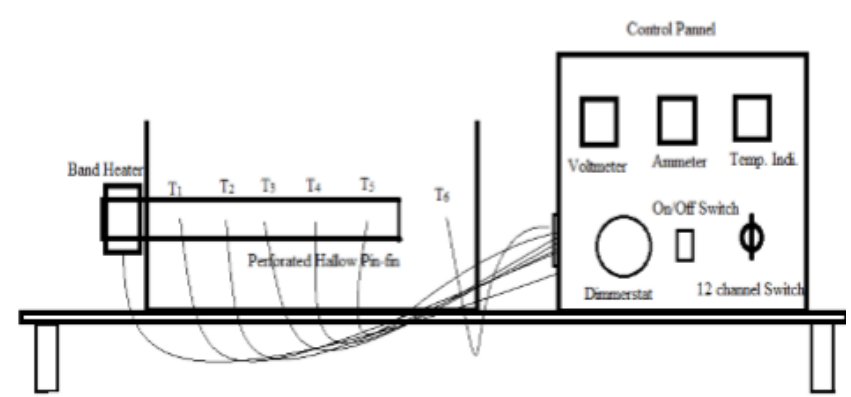

Fig. 1 Schematic Diagram of Experimental Setup 
Fig. 2 show the modeled figure of Pin-fin prepared for testing. Pin-fin of $125 \mathrm{~mm}$ long and $12.5 \mathrm{~mm}$ in diameter were prepared from copper as solid fin and another one having a length of $125 \mathrm{~mm}$ and an external diameter of 12.5 $\mathrm{mm}$ with the bore of $8.5 \mathrm{~mm}$.

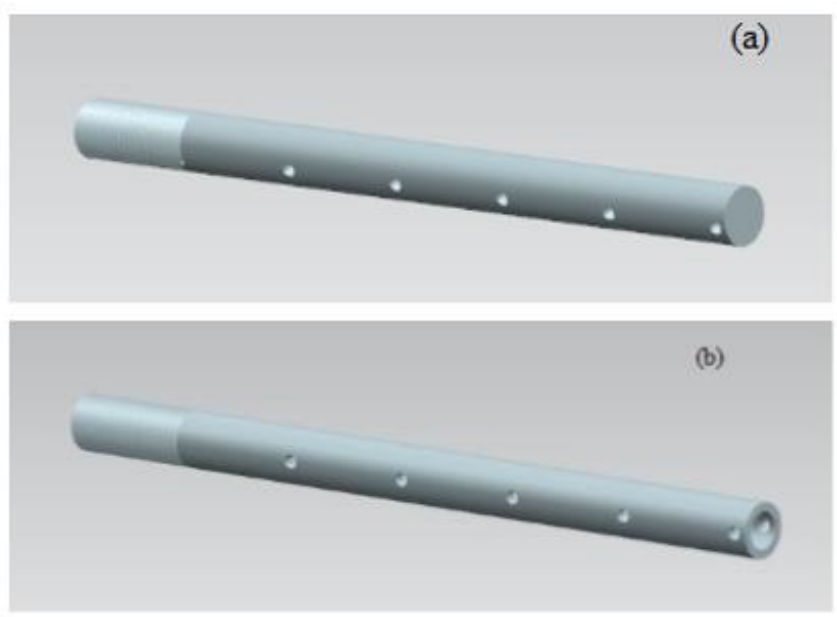

Fig. 2 (a) Solid Pin-fin (b) Hollow Pin-fin

The experiment was conducted for the different heat supplied which vary from $5 \mathrm{~W}$ to $30 \mathrm{~W}$ in 5 different steps. Convective heat transfer coefficient, temperature distribution and efficiency and effectiveness of the solid pin fin and hollow pin fin was compared.

\section{RESULT AND DISCUSSION}

1. Temperature distribution along the length of the Pin Fin

Temperature distribution for shortfin, adiabatic at the tip is expressed as

$$
\frac{t-t_{a}}{t_{i}-t_{a}}=\frac{\operatorname{Cosh}[m(L-x)]}{\operatorname{Cosh}(m L)}
$$

The temperature along the length of the pin fin was calculated theoretically is given in the equation (11). Theoretically obtained values of the temperatures were compared with the experimentally measured values for constant heat input of $110 \mathrm{~W}$ for both types of the fin. Temperature drop along the length of the fin is found to be more in case of the hollow fin in comparison with the solid fin. The values of temperature drop theoretically and experimentally are close and the difference in the theoretical and experimental value is due to the effect of radiation and is not considered in the theoretical. In the case of Hollow fin, the much larger difference in the theoretical and experimental value is because of the much larger value of radiation from the inside to the tube.

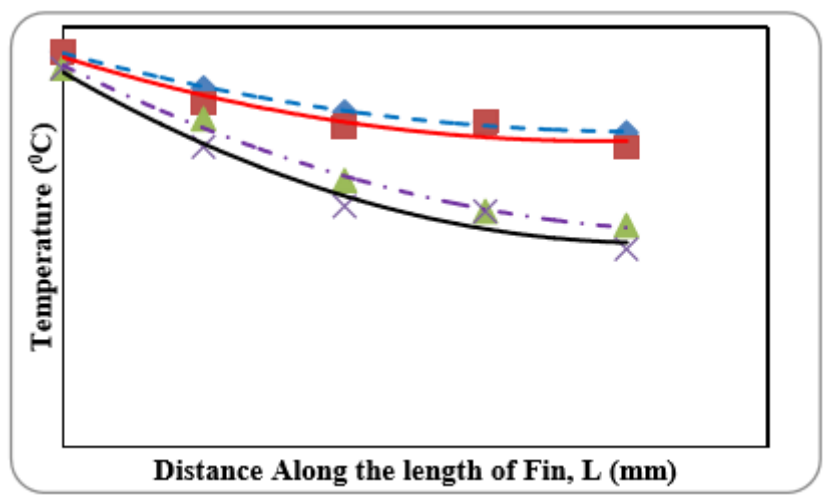

Fig. 2 Variation of temperature along the length of Pin Fin

2. Heat Transfer Coefficient and heat transfer in pin fin

Nusselt number plotted against the Rayleigh number with two different correlations i,e, Churchill Chough and Morgan Correlation. Morgan gives the better value for the nusselt number hence the Morgan correlation was used for calculating the value of convective heat transfer and heat transfer through the solid and hollow pin-fin. The Convective heat transfer coefficient along the length of the fin indicates that the rate of heat transfer is higher in case of hollow pin fin in comparison with the solid fin as shown in figure 3 . The experimental and theoretical convective heat transfer coefficient in case of the hollow fin is close to each other. However the in case of hollow pin fin there is the difference in the theoretical and experimental value. This is due to heat transfer from the inside.
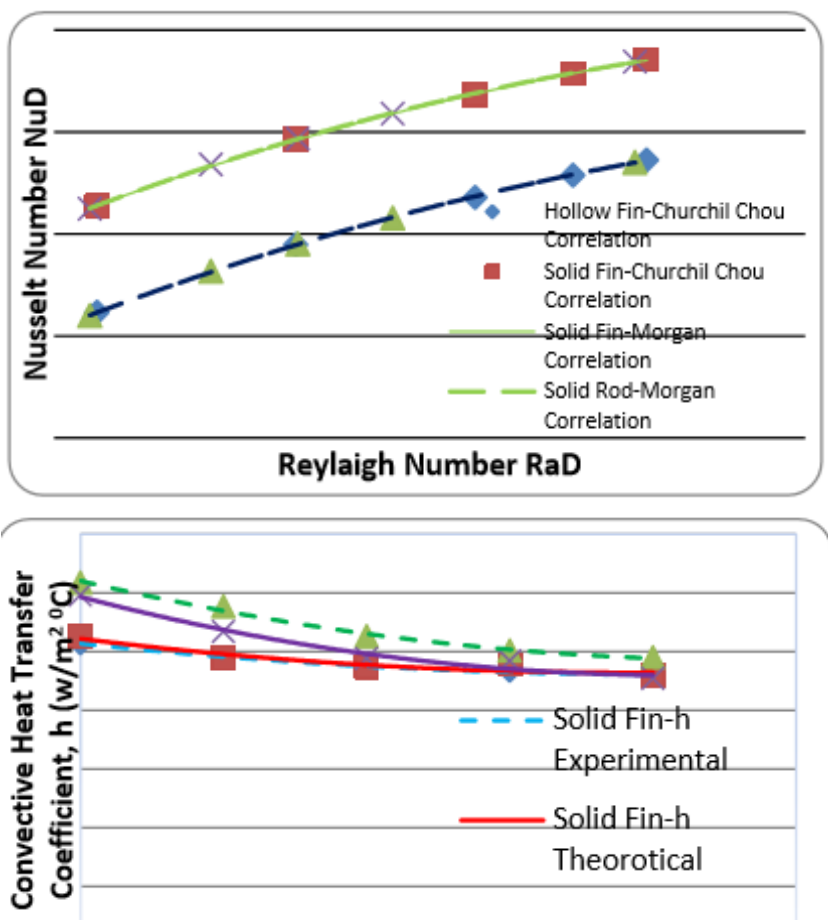

Distance Along the length of Fin, L...

Fig. 3 Variation of Nusselt Number with Rayleigh Number for hollow and Solid Pin fin. Fig. 4 Variation of Convective heat transfer coefficient along the length of Pin fin. 


\section{Efficiency and Effectiveness}

Efficiency for shortfin adiabatic at the end is given by equation [18].

$$
\eta=\frac{\tan h(m l)}{m l}
$$

The effectiveness of the fin is calculated as the ratio of $Q$ with a fin to the $\mathrm{Q}$ without a fin and is given by equation (13)

$$
\varepsilon=\eta \frac{P L}{A_{c s}}
$$

Efficiency and effectiveness plotted with the different heat flow as shown in the fig. 5 and fig. 6 respectively, shows that efficiency in case of the hollow fin is less compared to solid pin fin. The effectiveness of the hollow pin fin is almost the double and

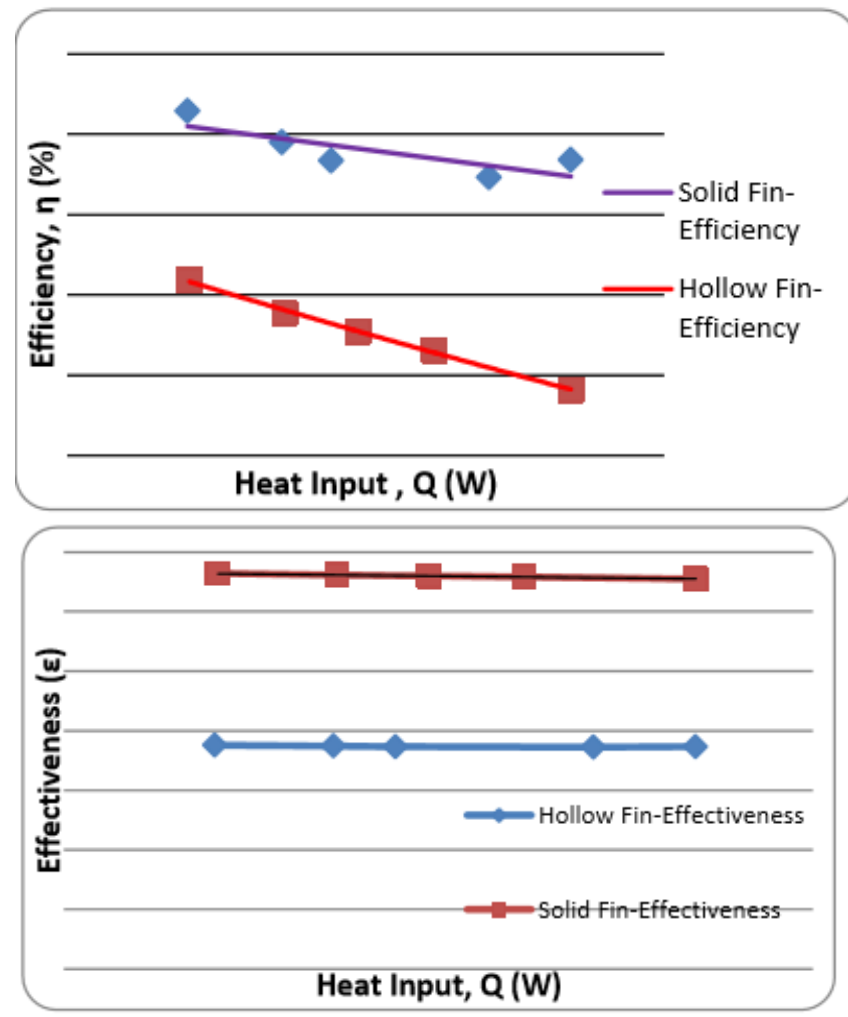

Figure 6. Efficiency variation with different heat input Figure7. The effectiveness of different heat input

Effectiveness is found to be 1.76 times more in hollow pin fin compared to the solid pin fin and constant with the increasing heat flow rate.

\section{CONCLUSION AND FUTURE SCOPE}

The experiment was conducted to analyze the natural convection around hollow pin fin, and compare thermal performance of hollow pin fin with the solid pin fin of same dimension and orientation. The experimental result of temperature distribution shows that the faster temperature drop along the length. The high value of convective heat transfer in the initial phase due to which faster temperature drop takes place. Convection is found to be dominating due to less area for conduction along the length. Theoretical value and experimental value are close to each for temperature distribution as well the convective heat transfer coefficient.

Efficiency is reduced in the case of hollow fin but the effectiveness of the hollow pin fin is increased by 1.76. From an economic point of view, the hollow pin fin is a more efficient solution. Further, the spacing of the hollow pin fin can be optimized and the optimum value of the inside diameter can be found out.

\section{ACKNOWLEDGMENTS}

The research is supported by the Department of Mechanical Engineering, Pimpri Chinchwad College of Engineering, Pune.

\section{REFERENCES}

1. E.M. Sparrow, J.W. Ramsey, C.A.C. Alterman, Experiments on in-line pin-fins arrays and performance comparison with staggered arrays, ASME J. Heat Transfer 102 (1980) 44-50.

2. K. Bilen, U. Akyol, S. Yapici, Heat transfer, and friction correlations and thermal performance analysis for a finned surface, Energy Convers. Manage. 42 (2001) 1071-1083.

3. W.A. Scott, Cooling of Electronic Equipment, John Wiley and Sons, New York, USA, 1974.

4. C.L.Chapman, S. Lee, B.L. Schmidt, Thermal performance of an elliptical pin fin heat sink, in 10th IEEE Semi-Therm, 1994, pp. 25-31.

5. W.A. Khan, R. Culham, M.M. Yovanovic, The role of fin geometry in heat sink performance, J. Heat Transfer 128 (2006) 324-330.

6. Kai-Shing Yang, Wei-Hsin Chu, Ing-Yong Chen, Chi-Chuan Wang, A comparative study of the airside performance of heat sinks having pin fin configurations, Int. J. Heat Mass Transfer 50 (2007) 4661-4667.

7. H.R. Seyf, M. Layeghi, Numerical analysis of convective heat transfer from an elliptic pin fin heat sink with and without metal foam insert, J. Heat Transfer 132 (2010) 071401-1-071401-9.

8. E.R. Meinders, T.H. Van Der Meer, K. HanJalic', Local convection heat transfer from an array of wall-mounted cubes, Int. J.Heat Mass Transfer 41 (1998) 335-346.

9. O.N. Sara, T. Pekdemir, S. Yapici, M. Yilmaz, Heat transfer enhancement in a channel flow with perforated rectangular blocks, Int. J. Heat Fluid Flow 22(2001) 509-518.

10. M.R. Shaeri, M. Yaghoubi, Numerical analysis of turbulent convection heat transfer from an array of perforated fins, Int. J.Heat Fluid Flow 30 (2009) 218-228

11. M.F. Ismail, M.N. Hasan, M. Ali, Numerical simulation of turbulent heat transfer from perforated plate-fin heat sinks, Heat Mass Transfer 50 (2014) 509-519.

12. S.B. Chin, J.J. Foo, Y.L. Lai, T.K.K. Yong, Forced convective heat transfer enhancement with perforated pin fins, Heat MassTransfer 49 (2013) 1447-1458.

13. Pop, D.B. Ingham, Convective Heat Transfer- Mathematical and Computational Modeling of Viscous Fluids and PorousMedia, Pergamon, 2001.

14. P.A. Deshmukh, R.M. Warkhedkar, Thermal performance of pin fin heat sinks $-\mathrm{a}$ review of the literature, Int. Rev. Mech. Eng. 5 (4) (2011) 726-732.

15. C.J. Kobus, T. Oshio, Development of a theoretical model for predicting the thermal performance characteristics of a vertical pin-fin array heat sink under combined forced and natural convection with the impinging flow, Int. J. Heat Mass Transfer 48 (2005) 1053-1063.

16. C.J. Kobus, T. Oshio, Predicting the thermal performance characteristics of staggered vertical pin fin array heat sinks under combined mode radiation and mixed convection with the impinging flow, Int. J. Heat Mass Transfer 48 (2005) 2684-2696.

17. R.C.Sachdeva, Fundamentals of engineering heat and mass transfer, New Age Publication (2000) 329-360.

18. P.K.Nag, Heat and mass transfer, Second Edition, Tata McGraw-Hill Publication (2007) 86-170. 